\title{
Opinion
}

\section{Dentists in Covid19 Mode}

\author{
Carlos Humeres Sigala* \\ Oral and Maxilofacial Pathology, Regional Hospital Antofagasta, Chile
}

\section{Opinion}

Dear, I want to share with you my opinion and reflection on what I have experienced these approximately 11 months of pandemic on this side of the world (South America).

I live in a regional capital city, Antofagasta, in northern Chile, where the first cases of SarsCov-2 began to be detected in midMarch 2020. At first, many sanitary measures taken globally were also implemented in Chile and South America, where dentists suffer quite harshly and abruptly from the arrival of COVID19. In our local case, I remember that a dentist was diagnosed with COVID19 when performing the PCR for presenting symptoms, and it turns out that the day before he had treated a number of patients no less.

Faced with this situation, in the first instance a large number of colleagues spoke about the irresponsibility of the dentist, since he had come from a vacation period in Brazil and apparently he had not respected the mandatory quarantine, which is not true because until that moment he had not There were measures on the part of the government to carry out a correct follow-up or traceability of the people who were arriving in the country through the only international terminal that Chile has, if as you read it, the only one.

Do you want to know the result of patient care by the dentist? Zero (0) infected patients. Do you want to know the result of the care of the mother of the dentist who works in the sale of fruits and vegetables and that she was also infected? Incalculable, 80 people to quarantine and the closure of the premises where she worked. You will understand that the panic associated with dental care seized both professionals and patients, which led to an abrupt stop of elective care, leaving only emergency care. This situation persisted for at least 6 months, where, on the one hand, a great ignorance of ourselves, the dentists themselves, was evidenced in being able to defend our way of working and, on the other hand, it was literally necessary to arm ourselves with personal protection elements (PPE) in order to be able to return to attend. Undoubtedly, mea- sures such as social distancing in waiting rooms, triage before telephone assistance, deferred attention for ventilation and use of barriers for administrative personnel are reasonable, but the business that was armed between supersonic extractors, suits astronaut type for safe care, ultraviolet lights, etc, etc, turned into a complete madness, which ended in that the return to care was postponed for several months to what was really required. They wondered why the dentist had no associated infections? Simply because we dentists have always been used to wearing PPE, some more specialties, others less, others in a better way or not, it has always been in our training in the first instance the washing of hands, followed by the use of gloves, masks, face shields, ejectors, ventilation, use of enzymatic detergents, and so on countless clinical actions. I ask you the following, when you have been cared for by other health professionals, how many nurses use gloves when vaccinating? How many doctors examine your skin, your oral cavity with a low tongue and without gloves? How many doctors perform procedures that can emit aerosols and only have a gown and underneath their clothes with which they go home? How many health professionals treat you with masks in narrow care, midwives, doctors, nurses, kinesiologists? I hope you are not offended, there is nothing against you, I only tell the reality.

We as dentists must and are the profession that should best handle the use of PPE, and probably with the case of our city, it was demonstrated that the correct use of gloves and masks was perhaps enough to avoid contagion to our patients and that also runs to the other side, for our protection.

Undoubtedly, all this new world situation for our generations has led us to be even more rigorous with the use of plastic bibs, clinical caps and face shields that perhaps we had well abandoned, but how important it is to highlight and emphasize that we are the professionals of the oral and maxillofacial territory, and we must defend that our care is safe, controlling actions in both public and private services, it does not depend on anyone but us that this is

\begin{tabular}{|l|l|}
\hline Quick Response Code: & *Corresponding author: Carlos Humeres Sigala, Oral and Maxilofacial Pathology, Regional \\
Hospital Antofagasta, Chile \\
Received: 15 February, 2021 \\
Citation: Carlos Humeres Sigala. Dentists in Covid19 Mode. SOJ Den Oral Disor. 2021;1(2):1-2. \\
\hline DOI: 10.53902/SOJDOD.2021.01.000506
\end{tabular}


fulfilled, thus leaving the stigma of dental care in "times of virus "It is high risk, since I want to remind everyone: patients, colleagues, health professionals and administrators that before COVID19, we daily lived with HIV, TB, Rotavirus, Epstein Barr, Cytomegalovirus, Candida spp, etc, etc. , and before this pandemic nobody talked about the risk of going to the dentist, nobody talked about super powerful dental extractors, ultraviolet lights eta or other things.

Finally, after all the above, I want to call on the international dental community to defend our competences, and that after the application of the vaccine and the standardization of care, these acts that border on ignorance are never repeated again and that nowadays, in a globalized world, they ended up harming no lesser part of our colleagues in private practice. Itis time towalkdifferently.

\section{Acknowledgments}

None.

\section{Funding}

None.

\section{Conflicts of interest}

Author declares that there is no conflict of interest. 